Esta revista forma parte del acervo de la Biblioteca Jurídica Virtual del Instituto de Investigaciones Jurídicas de la UNAM

\title{
La transparencia en las elecciones \\ y la comunicación judicial
}

\section{Salvador O. Nava Gomar}

\section{Sumario:}

I. El principio de transparencia en el Estado democrático

II. La transparencia en el ámbito electoral

III. La transparencia como factor de confianza en la decisión judicial

IV. La experiencia de la elección presidencial

V. Consideraciones finales

VI. Anexo 


\section{El principio de transparencia en el Estado democrático}

La relación entre transparencia, elecciones y legitimidad democrática es una cuestión fundamental en el Estado constitucional, la confianza en las instituciones y en los procedimientos electorales son elementos necesarios para la legitimidad de su resultado y del propio régimen democrático. De ahí que la Carta Democrática Interamericana, ${ }^{1}$ adoptada por la Organización de los Estados Americanos (OEA) en 2001, identifique a la transparencia de las actividades gubernamentales entre los componentes fundamentales del ejercicio de la democracia (artículo 4o.).

La vinculación entre transparencia y democracia ha sido ampliamente explorada por la doctrina y existe un consenso general en la función de la transparencia - entendida como la maximización del principio de publicidad de los actos públicos- como parte del sistema de control del poder que garantiza los derechos fundamentales, fomenta la deliberación pública y la vigencia del propio régimen democrático. No es necesario para efecto de esta exposición ahondar en ello, basta reiterar que, como lo afirma Ernesto Garzón Valdés, "lo que caracteriza a lo público es la transparencia" y la publicidad de los actos de las autoridades públicas "se convierte en un elemento esencial de todo Estado de Derecho".

Al respecto, la Corte Interamericana de Derechos Humanos, en el caso Claude Reyes y otros vs. Chile, destacó que:

El actuar del Estado debe encontrarse regido por los principios de publicidad y transparencia en la gestión pública, lo que hace posible que las personas que se encuentran bajo su jurisdicción ejerzan el control democrático de las gestiones estatales, de forma tal que puedan cuestionar, indagar y considerar si se está dando un adecuado cumplimiento de las funciones públicas. El acceso a la información bajo el control del Estado, que sea de interés público, puede permitir la participación en la gestión pública, a través del control social que se puede ejercer con dicho acceso. ${ }^{2}$

1 Cfr. Carta Democrática Interamericana aprobada por la Asamblea General de la OEA el 11 de septiembre de 2001 en el Vigésimo Octavo Periodo Extraordinario de Sesiones celebrado en Lima, Perú.

2 Cfr. Corte IDH, entre otros, caso Claude Reyes y otros vs. Chile, fondo, reparaciones y costas, sentencia del 19 de septiembre de 2006, serie C, núm. 151, p. 86. 
Además, en la aplicación del principio de transparencia, que informa el ordenamiento jurídico nacional y está previsto en el artículo 60. constitucional, destaca el positivo influjo de la reforma constitucional al artículo 1o. de la propia Constitución, por la cual se prescribe el criterio interpretativo para las normas relativas a derechos humanos (como lo son las relativas a la transparencia y la protección de datos), de conformidad con lo dispuesto en la propia Constitución federal y los tratados internacionales y para la consecución de una protección más amplia. Igualmente, se suma la obligación a cargo de las autoridades para promover, respetar, proteger y garantizar los derechos humanos, de conformidad con los principios de universalidad, interdependencia, indivisibilidad y progresividad.

\section{La transparencia en el ámbito electoral}

Como se destacó, el principio de transparencia o de máxima publicidad en el contexto de las elecciones democráticas es muy relevante. Sólo así es posible el ejercicio pleno de los derechos político-electorales fundamentales de votar, ser votado, asociación y afiliación, puesto que se requiere, la mayoría de las veces, contar con información respecto a los partidos y sus procesos internos a fin de definir una opción política ya sea para la emisión del sufragio, o para definir una militancia o una candidatura. Además, la organización transparente del proceso electoral es una condición necesaria de su validez y legitimidad, particularmente por cuanto hace al escrutinio y cómputo de la votación emitida y de los resultados de la elección.

En la materia electoral contamos con garantías primarias y secundarias (sustantivas, procedimentales e institucionales) que reconocen y salvaguardan el derecho a la información y la transparencia como valores indispensables del sistema democrático. Paulatinamente se ha abierto paso a una dinámica constitucional significativa a partir de los procesos de reforma legislativa y de la interpretación del Tribunal Electoral, el cual ha adoptado en mi concepto una posición clara a favor de la transparencia y el derecho a la información, dentro de los límites previstos en la legislación y aquellos derivados de la ponderación con otros derechos e intereses fundamentales. Lo que no supone que la jurisprudencia esté exenta de errores, imprecisiones o cuestio- 
namientos, ningún juez, tribunal o colegiado es ajeno a contradicciones o inconsistencias, lo fundamental, me parece, es la disposición abierta a la transparencia y a la deliberación crítica de sus resoluciones.

\section{La transparencia como factor de confianza en la decisión judicial}

En el ámbito judicial, la confianza en las resoluciones supone necesariamente la confianza en el proceso. La legitimación democrática de la decisión judicial pasa por la transparencia en las formas y en los procedimientos que permitan a la ciudadanía conocer de la manera más amplia y oportuna posible, no sólo el sentido de la determinación sino también los argumentos y razonamientos que la soportan, motivan y fundamentan.

El debido proceso abarca no sólo el respeto de aquellos derechos fundamentales que requiere una decisión imparcial sino también una comunicación judicial adecuada, a través de una motivación suficientemente razonada que tome en cuenta los argumentos de las partes y el acervo probatorio. Pero la legitimación democrática de la decisión judicial requiere también de un proceso de socialización adecuado.

Como lo he expuesto en otras ocasiones, ${ }^{3}$ la claridad y la sencillez de una sentencia permiten la consecución cabal de diversos objetivos indispensables para comunicar correctamente la decisión no sólo a las partes en el proceso sino también a la ciudadanía en general, entre ellos están: la plena justificación de la decisión judicial; el conocimiento de los destinatarios de la norma para su cumplimiento; el control de la actividad jurisdiccional y la rendición de cuentas a la ciudadanía como forma de control social.

La dimensión pragmática de la decisión judicial se orienta a su aceptabilidad racional y al consenso normativo de la determinación a través de la argumentación y la exposición clara de sus razonamientos. Ello contribuye también a la función didáctica y orientadora de la jurisprudencia constitucional, a su dimensión "pedagógica", pero tam-

3 Cfr. "Hacia un nuevo modelo de comunicación judicial", Quid Iuris, núm. 17, mayo de 2012, pp. 9-20. 
bién permite la crítica social sobre el trabajo judicial, lo cual resulta fundamental en una sociedad democrática abierta y plural.

El proceso de socialización exige también la adecuada publicidad de las sentencias y resoluciones judiciales, como una consecuencia del derecho a la información de las partes y de la ciudadanía. En dicho proceso la informática y las nuevas tecnologías son una herramienta fundamental que impone retos y propone metas antes insospechadas para la judicatura.

Las computadoras y la Internet, los dispositivos de captura y almacenamiento, las grandes bases de datos, los medios inalámbricos o hasta las redes sociales han transformado la manera en la que se genera la doctrina o incluso se litiga, y su interacción con la labor jurisdiccional es por demás estrecha: por una parte, ésta es esencialmente comunicadora y, por otra, está constreñida a superar sus alcances de difusión. Si bien la tecnología, en general, distaba mucho de ser la clave para que un juzgador se comunicara con sus pares, con las partes y con la ciudadanía, en la actualidad se habla, incluso, de una "e-justice" o de "oficinas judiciales tecnológicamente avanzadas".

De esta forma, las tecnologías informáticas y los medios de comunicación derivados de ellas han cambiado las dinámicas de trabajo, pero, sobre todo, han transformado la manera en la que se intercambia la información, democratizando sus ámbitos de influencia en un sentido por primera vez ilimitado en términos reales y efectivos, poniendo prácticamente al alcance de cualquier persona, en cualquier parte del mundo, el debate jurídico y sus principales directrices, emanadas de la jurisprudencia y la doctrina.

La experiencia ha demostrado que en las nuevas oleadas tecnológicas la judicatura debe aprender no sólo a nadar sino también a surfear. Si el juez es un comunicador del derecho, entonces debe necesariamente evolucionar a la par de los instrumentos tecnológicos que hacen las veces de vehículo entre el juez y la sociedad.

En sociedades cada vez más plurales y democráticas, transparentar las decisiones de los jueces ya no sólo implica su mera publicación en estrados, periódicos o gacetas oficiales, ello es necesario pero no suficiente, es preciso extender sus alcances a un público más amplio, en el entendido de que los medios e instrumentos utilizados para su difusión son cada vez más amplios y accesibles. 
Así lo expresan, por ejemplo, las denominadas Reglas de Heredia o Reglas Mínimas para la Difusión de Información en Internet, ${ }^{4}$ las cuales consideran que las finalidades de la difusión en Internet de las sentencias y resoluciones judiciales son el conocimiento de la información jurisprudencial y la garantía de igualdad ante la ley, y procurar alcanzar la transparencia de la administración de justicia. Asimismo, la Declaración Copán-San Salvador adoptada por el IV Encuentro Iberoamericano de Consejos de la Judicatura y la VIII Cumbre Iberoamericana de Presidentes de Cortes Supremas y Tribunales Supremos de Justicia de $2004,{ }^{5}$ entre sus declaraciones en áreas temáticas puntualizó la incorporación de las nuevas tecnologías en la administración de la justicia como un imperativo de la era de la "sociedad de la información", que puede contribuir a elevar la eficiencia y con ello la confianza de la sociedad en los sistemas judiciales, lo que conlleva también un cambio cultural para la comunidad jurídica, declarando que "la incorporación de las nuevas tecnologías en la administración de justicia debe ser considerado un instrumento indispensable que proporcione eficiencia, eficacia, celeridad y calidad en el trabajo judicial, tanto en la parte jurisdiccional como administrativa".

En congruencia con esta tendencia, el Tribunal Electoral del Poder Judicial de la Federación ha implementado diferentes herramientas de difusión de las decisiones judiciales.

En el reciente proceso electoral federal y particularmente a fin de hacer frente y trasparentar lo más posible el proceso de tramitación, sustanciación y resolución de las impugnaciones de la elección presidencial, el tribunal incorporó no sólo mecanismos de difusión de sus resoluciones, sino también instrumentos tecnológicos para el puntual seguimiento de las diferentes actuaciones jurisdiccionales y administrativas relacionadas con la impugnación de la elección presidencial por nulidad de la misma, como lo fue, por ejemplo, el Sistema de Información de las Elecciones Federales (SIEF).

4 Adoptadas por el Seminario-Taller Internet y Sistema Judicial en América Latina y el Caribe, Heredia (Costa Rica), 8 y 9 de julio de 2003. La reunión contó con la participación de varios ministros y magistrados de Cortes Supremas de América del Sur, y Central.

5 Las reuniones en la ciudad de Copán Ruinas, los días 21 y 22 de junio de 2004, así como en la ciudad de San Salvador, El Salvador, los días 24 y 25 del mismo mes y año, durante la celebración en forma conjunta y sucesiva del IV Encuentro Iberoamericano de Consejos de la Judicatura y la VIII Cumbre Iberoamericana de Presidentes de Cortes Supremas y Tribunales Supremos de Justicia. 


\section{La experiencia de la elección presidencial}

Con motivo de la reforma electoral de 2007-2008, se incorporó expresamente la posibilidad de impugnar la elección presidencial por nulidad de toda la elección. De la misma forma se establecieron reglas para el recuento de la votación en sede jurisdiccional con motivo de la impugnación de los cómputos distritales. Para la adecuada recepción de las impugnaciones, la integración de los expedientes y la sustanciación de los mismos, así como, en su caso, la realización de recuentos de votación, se hizo necesario la adopción de diferentes medidas administrativas que hicieran no sólo más eficiente la tramitación de los asuntos en sus diferentes etapas procesales, sino también más transparente y de más fácil conocimiento por las partes, los medios de comunicación y por la ciudadanía.

En particular, quiero destacar los trabajos realizados con motivo de la impugnación de la elección presidencial por nulidad de toda la elección presentada por la coalición Movimiento Progresista, que se tramitó en el expediente identificado con la clave SUP-JIN-359/2012.

Para tal efecto se realizaron las actuaciones siguientes:

a) Integración oportuna de la Comisión Encargada de Elaborar el Cómputo. Con base en lo dispuesto por el artículo 123 del Reglamento Interno del Tribunal Electoral, la Sala Superior debe designar, con el número de integrantes que estime conveniente, una comisión de magistrados, para que procedan a la elaboración del dictamen sobre el cómputo final de la elección y la calificación de la elección y la de presidente electo.

Sobre esa base, el 25 de junio de 2012, en sesión privada, los magistrados integrantes de la Sala Superior, por unanimidad de votos, designaron a los magistrados Constancio Carrasco Daza, Flavio Galván Rivera y Salvador Olimpo Nava Gomar como integrantes de la Comisión Encargada de Elaborar el Proyecto de Cómputo Final y, en su caso, la Declaración de Validez y la de Presidente Electo de los Estados Unidos Mexicanos. Dicha determinación fue dada a conocer a través del Diario Oficial de la Federación del 17 de julio de 2012, así como en los estrados de la Sala Superior y en las páginas de Internet e intranet. 
Es importante destacar que dicha designación se realizó, a propuesta del magistrado presidente José Alejandro Luna Ramos, antes de que tuviera verificativo la jornada electoral para renovar a los titulares de los poderes Legislativo y Ejecutivo de la Unión.

A diferencia de lo ocurrido en los dos últimos procesos, la comisión se integró con tres magistrados de la Sala Superior, porque se permitía una conformación más plural y, a la vez, coadyuvaría en el adecuado desahogo de los trabajos que tuvo asignados la comisión.

b) Creación del micrositio. La primera decisión que adoptó la comisión encargada de elaborar el cómputo, fue la creación de un micrositio en la página oficial electrónica del Tribunal Electoral, en el cual se divulgaron sus actividades y publicaron sus decisiones jurisdiccionales.

c) Agenda de la comisión. Otra de las decisiones de la comisión instructora fue la publicación de su agenda. En dicha sección del micrositio, por ejemplo, se divulgó lo relativo a la reunión de los magistrados comisionados con los representantes de la coalición Movimiento Progresista y el Partido Revolucionario Institucional para la recepción de alegatos verbales.

d) Integración de secretarios a los trabajos de la comisión. El 28 de julio de 2012 se acordó integrar dos secretarios instructores y ocho secretarios de estudio y cuenta a los trabajos procesales de la comisión encargada de elaborar el proyecto.

e) 41 días para la elaboración del proyecto. Desde el turno del juicio de inconformidad sobre nulidad de la elección presidencial, el 18 de julio de 2012, hasta la presentación del proyecto de sentencia a los demás magistrados de la Sala Superior, el 27 de agosto, transcurrieron 41 días.

f) Emisión de 44 acuerdos sobre sustanciación. La comisión dictaminadora emitió 44 acuerdos del 20 de julio al 29 de agosto de 2012, sobre recepción y radicación del expediente y sus anexos; admisión de la demanda; ordenación de la diligencia de apertura de cajas con pruebas; recepción de las llamadas pruebas supervenientes; ordenación de vistas; integración de cuadernos incidentales; recepción de pruebas y documentación de la Unidad de Fiscalización de los Recursos de los Partidos Políticos, así como de informes del Consejo General, de dicha Unidad de Fiscalización, y de la Secretaría Ejecutiva del Instituto Federal Electoral; 
solicitudes de la Fiscalía Especializada para la Atención de Delitos Electorales, y de comparecencia de la coalición tercera interesada y de firmas de los llamados apoyos de diversos ciudadanos a la demanda de la coalición actora, entre otras actuaciones.

g) Requerimientos de informes y pruebas para mejor proveer. En el micrositio se refiere la existencia de 8 acuerdos que estuvieron vinculados con la elaboración y desahogo de requerimientos para allegar mayores elementos de convicción al juicio.

h) Programas televisivos y otros videos. En el micrositio se da cuenta también de cinco programas de televisión: uno en televisión abierta y los demás en el Canal Judicial (uno como Proceso 2012 y tres en Justicia Electoral a la Semana). Asimismo, en el micrositio, aparecen dos videos. Uno de ellos es de una visita al Centro de Recepción de Expedientes Electorales Federales y otro más de la recepción del juicio de inconformidad por nulidad de la elección presidencial presentado por la coalición Movimiento Progresista.

i) Sentencia y ocho flujogramas. En el micrositio aparece el archivo electrónico de la sentencia SUP-JIN-359/2012, así como 8 flujogramas (una página para cada uno de ellos) en los que se resume el texto de 1346 páginas de la sentencia respectiva, con la temática siguiente:

1) Adquisición encubierta de tiempos en radio y televisión.

2) Uso indebido de encuestas y estudios de opinión.

3) Financiamiento encubierto por conducto del Banco Monex.

4) Agravios relacionados con tiendas Soriana.

5) Gastos excesivos en propaganda electoral y publicidad.

6) Intervención de gobiernos (federal y locales).

7) Compra y coacción del voto antes, durante y después de la jornada electoral.

8) Irregularidades durante los cómputos distritales.

j) Cuatro resoluciones sobre incidentes. Además de la elaboración del proyecto de sentencia del juicio de inconformidad por nulidad de la elección presidencial, la preparación del proyecto de cómputo final de la elección presidencial y de las relativas a las Declaraciones de Validez de la Elección y de Presidente Electo, la Comisión Encargada de Elaborar el Cómputo Final preparó los siguientes cuatro proyectos adicionales: 
1) Incidente sobre solicitud de excitativa de justicia.

2) Incidente sobre escritos de terceros interesados.

3) Incidente sobre escrito de coadyuvante (Andrés Manuel López Obrador).

4) Incidente sobre escrito de tercero interesado (Hugo Amós Torres Pluma).

Cada una de estas resoluciones constituyó un paso más hacia la resolución de fondo y su publicación en Internet permitió conocer, no sólo a las partes e interesados, sino a la ciudadanía en general el avance en el análisis de los temas y solicitudes involucradas en los mismos.

e) Incorporación de índices de contenido. Finalmente, es conveniente destacar que la Sala Superior, a propuesta de la Comisión, incorporó como parte de las resoluciones un índice de su contenido con la finalidad de facilitar la identificación del mismo.

\section{Consideraciones finales}

Las medidas adoptadas por la comisión para la calificación presidencial y aquellas aprobadas por la Sala Superior a propuesta de aquella, suponen, en mi concepto, un aspecto novedoso en el proceso de socialización y transparencia de las resoluciones judiciales que debe destacarse.

Es verdad que existen limitaciones a los esfuerzos por hacer pública la información judicial que impone la propia naturaleza de la función jurisdiccional, la cautela no sólo en la publicación de ciertos datos personales sino también la necesaria garantía de principios procesales, tales como la igualdad procesal de las partes. Es preciso advertir también que este fue un ejercicio novedoso y pionero en el ámbito de la justicia electoral por lo que su alcance y pertinencia deben valorarse en función de su eficacia a fin de perfeccionarse en función de las necesidades de la administración de justicia y de las posibilidades tecnológicas.

En lo fundamental, con tales medidas se buscó que las partes y la ciudadanía interesada pudieran acompañar, en la medida de lo posible, el proceso de deliberación del asunto y en buena medida pudiera, 
con posterioridad a su resolución, conocer los argumentos y, en su caso, criticarlos con fundamento.

Desde el momento de hacerse pública la sentencia y hasta la fecha se ha generado un proceso de deliberación pública sobre su sentido. Es necesario ( $y$ también se ha hecho ya) un análisis pormenorizado de su contenido, a fin de que se analicen, discutan y critiquen tanto y tan profundamente como el interés público y social lo exijan.

Ello es posible, en parte, por la transparencia en la comunicación de las sentencias de los tribunales de justicia. Como lo señalan, por ejemplo, los Principios de la Ética Judicial Iberoamericana, la transparencia es "una garantía de la justicia de sus decisiones" (artículo 56). Asimismo, se destaca que los jueces deben procurar ofrecer, sin infringir el derecho vigente, información útil, pertinente, comprensible y fiable (artículo 57) y documentar, en la medida de lo posible, todos los actos de su gestión y permitir su publicidad (artículo 58).

En mi concepto estos principios se han cumplido plenamente por la Sala Superior del Tribunal Electoral del Poder Judicial de la Federación en el proceso de resolución de las impugnaciones de la elección presidencial, de su calificación y declaración de validez de la elección y de presidente electo, y con ello se dio un paso más en la construcción de un nuevo modelo de comunicación de las decisiones judiciales que debe perfeccionarse en un futuro en beneficio de la administración de justicia, pero fundamentalmente, en beneficio de la ciudadanía y con ello de la democracia constitucional.

\section{Anexo}

Numeralia relacionada con la elección presidencial y el SUPJIN-359/2012 (Información del IFE y del TEPJF)

1. Datos previos a la jornada electoral de las elecciones federales $y$ locales concurrentes

- 2127 cargos de elección popular a elegirse (presidente de la República, 500 diputados federales, 128 senadores, 6 gobernadores y un jefe de gobierno, 579 diputados locales, 876 ayuntamientos, 16 jefes delegacionales y 20 juntas municipales). 
- El padrón electoral estuvo compuesto por un total de $\mathbf{8 4 4 6 4 7 1 3}$ ciudadanos.

- La lista nominal se integró por 79454802 ciudadanos.

- Casi una tercera parte del padrón electoral (28.33\%) fueron jóvenes de 18 a 29 años de edad. Por ende, $\mathbf{2 3} 926223$ jóvenes tuvieron la oportunidad de ejercer su derecho al voto.

- 2,335 concesionarios y permisionarios de radio y televisión integraron el catálogo de medios del IFE (1594 emisoras de radio y 741 emisoras de televisión).

- $\mathbf{1 8 8 9}$ pautas específicas para el proceso electoral federal (72\% de radio y $\mathbf{2 8 \%}$ de televisión).

- 133095 órdenes de transmisión elaboradas y entregadas a medios de comunicación.

- 4837 supervisores electorales.

- 29497 capacitadores asistentes electorales.

2. Presupuesto para el proceso electoral federal

- Presupuesto del IFE (incluyendo las prerrogativas de los partidos políticos): \$15296936922.38

- Financiamiento para gastos de campaña:

- PAN (\$424 784 163.94)

- PRI (\$537 269854.03$)$

- PRD (\$225745363.72)

- PT (\$118098 139.85)

- PVEM (\$156507 101.22)

- MC (\$103060 128.93)

- PANAL (\$115095669.09)

- Tope de gastos de precampaña para la elección presidencial: $\$ 67222416.83$

- Tope de gastos de campaña para la elección presidencial: $\$ 336112084.16$

3. Datos de la jornada electoral

- La votación total cuantificada fue de $\mathbf{5 0 3 2 3} 153$ votos.

- El porcentaje de participación fue del $\mathbf{6 3 . 3 4 \%}$

- Se emitieron 40737 votos de mexicanos en el extranjero, que se recibieron desde 91 países. 
- 79454802 ciudadanos inscritos en la Lista Nominal.

- 143130 de las 143132 casillas se instalaron.

- Se instalaron el $\mathbf{9 9 . 9 8 \%}$ de las casillas el día de la jornada electoral.

- 572528 ciudadanos integraron las Mesas Directivas de Casilla.

- De las 143132 mesas receptoras de votos aprobadas, 66526 fueron básicas, 69602 contiguas, 6102 extraordinarias y 902 especiales en todo el territorio nacional.

- Participaron 21091 ciudadanos como observadores electorales ciudadanos, es decir, una cobertura del $\mathbf{1 4 . 7 8 \%}$ de las casillas instaladas.

- La representación partidista en las mesas receptoras de votación, el Partido Acción Nacional (PAN) cubrió 70.31\% de los espacios; el Revolucionario Institucional (PRI), 91.52\%; el de la Revolución Democrática (PRD), 50.26\%; el Verde Ecologista de México, 41.16\%, el del Trabajo (PT), 50.66\%; Movimiento Ciudadano, $\mathbf{2 8 . 8 4 \%}$, y Nueva Alianza, $\mathbf{5 0 . 4 6 \%}$.

- La diferencia de votos entre Enrique Peña Nieto y Andrés Manuel López Obrador fue de 3,329,785 votos.

- La diferencia porcentual entre ambos candidatos fue de $\mathbf{6 . 6 2 \%}$

4. Datos de la jornada electoral

- Tras 24 horas de operación ininterrumpida y 426510 actas capturadas, el Programa de Resultados Electorales Preliminares detuvo, como lo marca la ley, su operación en punto de las 20:00 horas.

5. Datos sobre cómputos distritales y recuentos administrativos

- Los 300 Consejos Distritales y los 32 Consejos Locales se instalaron en tiempo y forma para realizar los cómputos.

- Toda la estructura ejecutiva desconcentrada del órgano, en total 1800 consejeros distritales y casi 4000 representantes de todos los partidos políticos intervinieron en los cómputos distritales.

- La elección presidencial exigió apertura de 78469 paquetes electorales, lo que representó el $\mathbf{5 4 . 8 \%}$ de las casillas a escala nacional. 
6. Datos de la demanda, informe circunstanciado y escrito de comparecencia del tercero interesado

- La demanda del juicio de inconformidad se presentó el 12 de julio de 2012 ante la Secretaría Ejecutiva del IFE.

- La demanda consta de $\mathbf{6 3 9}$ fojas.

- El alcance al escrito de demanda consta de 49 fojas.

- El informe circunstanciado consta de 334 fojas.

- El escrito de tercero interesado consta de $\mathbf{1 5 9 7}$ fojas .

\section{Datos del acervo probatorio}

- La actora acompañó a su demanda 34 cajas con pruebas.

- El 14 de agosto de 2012 la coalición actora ofreció 56 cajas con "pruebas supervenientes".

- En total, la coalición actora aportó más de 10000 elementos probatorios al juicio.

- La responsable acompañó al informe circunstanciado 8 cajas con pruebas (principalmente, actuaciones de expedientes de las quejas que se desahogan ante la Unidad de Fiscalización).

- En total, existen más de $\mathbf{1 5 0 0}$ elementos probatorios remitidos por la autoridad administrativa electoral al juicio (acuerdos, resoluciones, actuaciones de expedientes de quejas, entre otros aspectos).

- El tercero interesado acompañó a su escrito de comparecencia 4 cajas con pruebas (principalmente ejemplares de periódicos e informes de monitoreo).

8. Datos de actuaciones de la Comisión encargada de elaborar el proyecto de calificación jurisdiccional y, en su caso, la declaración de validez de presidente electo de los Estados Unidos Mexicanos

- El 18 de julio de 2012 se turnó el expediente a la Comisión Dictaminadora.

- Transcurrieron 44 días desde que se turnó la demanda a la Comisión, hasta que se dictó la sentencia.

- La Comisión dictaminadora emitió 45 acuerdos del 20 de julio al 29 de agosto de 2012. 
- 8 acuerdos estuvieron vinculados con la elaboración y desahogo de requerimientos para allegar mayores elementos de convicción al juicio.

\section{Información relacionada con la calificación de la elección de Presidente de los Estados Unidos Mexicanos (Información de la Dirección General de Estadística e Información Jurisdiccional)}

\begin{tabular}{|c|c|}
\hline RUBRO & NÚMERO \\
\hline Juicio de inconformidad & $\begin{array}{c}\text { Fondo: } 350 \\
\text { Desechamiento: } 27 \\
\text { Sobreseimiento: } 1\end{array}$ \\
\hline Casillas en las que se ordenó recuento & 1,125 \\
\hline Casillas anuladas & 526 \\
\hline $\begin{array}{c}\text { Incidentes de calificación de votos reservados juicio } \\
\text { de inconformidad }\end{array}$ & 52 \\
\hline Incidentes de nuevo escrutinio y cómputo & $\begin{array}{c}\text { Total: } 287 \\
\text { Ordenó recuento en: } 134\end{array}$ \\
\hline
\end{tabular}

\begin{tabular}{|c|c|}
\hline Votos anulados por partidos & Número \\
\hline PAN & 55317 \\
\hline PRI & 52782 \\
\hline PRD & 29098 \\
\hline PVEM & 2810 \\
\hline PT & 3600 \\
\hline MC & 4641 \\
\hline Nueva Alianza & 4513 \\
\hline PRI-PVEM & 14071 \\
\hline PRD-PT-MC & 8903 \\
\hline PRD-PT & 1660 \\
\hline PRD-MC & 659 \\
\hline PT-MC & 346 \\
\hline Total & 178400 \\
\hline
\end{tabular}

